\title{
Allied health growth: what we do not measure we cannot manage
}

\author{
Daniela Solomon ${ }^{1}$, Nicholas Graves ${ }^{1 *}$ and Judith Catherwood ${ }^{2}$
}

\begin{abstract}
Background: Data describing the Australian allied health workforce is inadequate and so insufficient for workforce planning. National health policy reform requires that health-care models take into account future workforce requirements, the distribution and work contexts of existing practitioners, training needs, workforce roles and scope of practice. Good information on this workforce is essential for managing services as demands increase, accountability of practitioners, measurement of outcomes and benchmarking against other jurisdictions. A comprehensive data set is essential to underpin policy and planning to meet future health workforce needs.

Discussion: Some data on allied health professions is managed by the Australian Health Practitioner Regulation Agency; however, there is limited information regarding several core allied health professions. A global registration and accreditation scheme recognizing all allied health professions might provide safeguards and credibility for professionals and their clients.

Summary: Arguments are presented about inconsistencies and voids in the available information about allied health services. Remedying these information deficits is essential to underpin policy and planning for future health workforce needs. We make the case for a comprehensive national data set based on a broad and inclusive sampling process across the allied health population.
\end{abstract}

Keywords: Allied health, Registration, Service provision

\section{Background}

The National Registration and Accreditation Scheme (NRAS) for Health Professionals was introduced in 2010. Ten professions previously registered in every state and territory joined the scheme upon commencement, and four subsequently, with representative national boards overseen by The Australian Health Practitioners Regulation Agency (AHPRA) [1]. Consequently, many established allied health professions have been excluded from the scheme: dietetics, speech pathology, audiology, exercise physiology, orthotists/prosthetists, social work and sonography. This is despite the Productivity Commission recommending at the outset of consultations that registration should occur at as broad a level as possible, consistent with maintaining quality and safety [2]. Over 50000 practitioners remain outside of the framework of

\footnotetext{
* Correspondence: n.graves@qut.edu.au

'Institute of Health Biomedical Innovation (IHBI), School of Public Health and Social Work, Queensland University of Technology, 60 Musk Ave. Kelvin Grove, Brisbane 4059, Australia

Full list of author information is available at the end of the article
}

provider accountability and hence patient safety [3]. In February 2011, the Australian Health Ministers Advisory Council (AHMAC) released a consultation paper recommending deferring consideration of inclusion of any additional professions [4]; some 20 proposals from health professions seeking inclusion in the NRAS have been adjourned, despite having addressed the 6 benchmarking criteria underscoring the public benefit of improved practitioner regulation as set out by the Intergovernmental Agreement for the NRAS [5]. Thus, less than a quarter of $50+$ health professions as defined by the Health Professionals and Support Services Award 2010 are represented [3].

\section{Main text \\ Current registration}

Public trust is predicated on the expectation that a formal regulation structure exists which provides recognition of qualifications, minimum entry standards, assurance of practice standards, a code of conduct and ethics and an avenue for complaints as argued by the National Alliance 
of Self-Regulating Health Professions (NASRHP) [3]. A recent survey demonstrated that the general public believe they have far greater protection against inappropriate and poor practice with respect to allied health practitioners than they do [6]. The more than 6 million visits to AHPRA's website and its online register of practitioners in addition to the 310000 customer service phone calls in the first half of 2011 suggest a requirement for a minimum level of transparency. The role of AHPRA as public safeguard has been emphasized in an analysis of postregistration data by Lin and Gillick [7].

Professional indemnity insurance is not mandatory for several non-AHPRA allied health professions (Table 1). Representative bodies for these professions provide an important regulatory role; however, association membership varies from state to state and between disciplines, with estimates of $60 \%$ for speech pathologists to $80 \%$ of dieticians [8]. Accreditation programmes are entirely voluntary. For self- or unregulated professions, few of the components of professional accountability are mandatory or enforceable [8]. Where clinical practice guidelines exist, adherence to these professionally defined standards is inconsistent [8]. There is no legislated registration for disciplines such as social work even though there are an estimated 22000 [9] social workers employed in a diverse range of settings, with some of the most disadvantaged and vulnerable members of the community utilizing their services. Social work remains the largest unregistered health profession, providing services often in rural and remote locations where they are the sole provider of essential counselling and therapy to communities increasingly burdened by mental health issues, yet less than $40 \%$ of social workers belong to their professional association at a time when social workers are playing a critical role in the management of mental health disorders [6]. Although a self-regulatory system currently exists within the Australian Association of Social Work (AASW) for managing ethics complaints, only members can be investigated through this process, with the most severe penalty provided under this system being exclusion from eligibility for membership, enabling practise as a counsellor or therapist. The problems associated with loopholes whereby practitioners switching professional titles can evade the regulatory net have been well-documented [7]. Published statistics for the widely accessed Medicare-subsidized Enhanced Primary Care and Chronic Disease Management (CDM) schemes show dieticians among the highest allied health service providers for each year [10], yet dieticians have no requirements to be registered in any state or territory and, thus, no legally enforceable set of probity, qualification and practice standards and no measure of certainty of competence and ethical practice for the members of the public. Registration of speech pathologists in Queensland was in fact recently discontinued by the only state government formerly requiring it, despite the growing need for speech pathology intervention [11].

\section{Workforce data-getting ahead of the curve}

There is currently no comprehensive national source of allied health workforce data. This has implications for current and future health workforce planning and policy development for the health sector, as robust, reliable and timely data are essential to successful health workforce planning [12]. This has been acknowledged in the US

Table 1 Allied health professions (non-AHPRA) membership and coverage

\begin{tabular}{|c|c|c|c|c|c|c|}
\hline & Audiology & Dietetics & $\begin{array}{l}\text { Orthotics/ } \\
\text { prosthetics }\end{array}$ & $\begin{array}{l}\text { Speech } \\
\text { pathology }\end{array}$ & Sonography & Social work \\
\hline $\begin{array}{l}\text { Current publicly } \\
\text { accessible national } \\
\text { register of registered } \\
\text { practitioners }\end{array}$ & $\begin{array}{l}\text { List of clinics and public } \\
\text { and private services } \\
\text { by region }\end{array}$ & $\begin{array}{l}\text { Yes, including } \\
\text { expelled/ } \\
\text { suspended } \\
\text { members }\end{array}$ & Yes & Yes & No & $\begin{array}{l}\text { Yes, including list } \\
\text { of conditional and } \\
\text { ineligible members } \\
\text { (ethics breach) }\end{array}$ \\
\hline $\begin{array}{l}\text { Practitioners } \\
\text { represented } \\
\text { (approx.\%) }\end{array}$ & $98 \%$ & $80 \%$ & $75 \%$ & $60 \%$ & $70 \%$ & $40 \%$ \\
\hline $\begin{array}{l}\text { Accreditation status } \\
\text { available }\end{array}$ & No & Yes & Yes & Yes & No & Yes \\
\hline $\begin{array}{l}\text { Professional } \\
\text { indemnity }\end{array}$ & $\begin{array}{l}\text { Mandatory for practitioners } \\
\text { in private practice and } \\
\text { contract or sessional work } \\
\text { or if employed by DVA, } \\
\text { WorkCover, etc. }\end{array}$ & Not mandatory & $\begin{array}{l}\text { Not mandatory PI, } \\
\text { PL and products } \\
\text { liability recommended } \\
\text { by AOPA }\end{array}$ & $\begin{array}{l}\text { Not } \\
\text { mandatory }\end{array}$ & $\begin{array}{l}\text { Not mandatory. } \\
\mathrm{PI} \text { and } \mathrm{PL} \text { provided } \\
\text { to ASA members } \\
\text { only }\end{array}$ & $\begin{array}{l}\text { Not mandatory. PI } \\
\text { and PL provided } \\
\text { to AASW members } \\
\text { only }\end{array}$ \\
\hline Complaints $^{a}$ & & & & $\begin{array}{l}\text { Referred to } \\
\text { senior advisor } \\
\text { professional } \\
\text { issues }\end{array}$ & $\begin{array}{l}\text { Referred to } \\
\text { disciplinary } \\
\text { committee }\end{array}$ & $\begin{array}{l}\text { Ethics Complaints } \\
\text { Management } \\
\text { Process }\end{array}$ \\
\hline
\end{tabular}

AASW, Australian Association of Social Workers; DVA, Department of Veteran Affairs; PI, Private Insurance; PL, Public Liability; AOPA, Australian Orthotic Prosthetic Association; ASA, Australian Sonographers Association.

${ }^{a}$ Only applies to members of professional organizations. Complaints about non-members directed to the relevant state government service. 
where minimum data sets are being developed at a national level through the Health Resources and Services Administration National Centre for Health Workforce Analysis [13], and in England, the Department of Health has the Centre for Workforce Intelligence [14] as the national authority on workforce planning. The recent 'Review of Australian Government Health Workforce Programs, Mason Review' available from the Australian Department of Health Website dealt with Australian Government Health Workforce Programmes and made the point that reliable data sources are limited for the allied health workforce. This review called for better data collection across settings to provide information for policy development and made special mention of the disability sector that is now being reformed by the introduction of the National Disability Insurance Scheme.

Workforce Reports (National Health Labour Force Series) with a range of data have been produced by the Australian Institute of Health and Welfare (AIHW) [15] for a limited number of allied health professions (physiotherapists, occupational therapists and podiatrists), but no such reports have been produced for audiology, dietetics, speech pathology or radiography, although this is changing with the introduction of the HW 2025 series by Health Workforce Australia which will provide coverage of 40 professions [16]. Accurate reporting of current service provision and determining projections regarding future supply and demand is not possible for a number of allied health professions. For example, there is currently no substantive data available across the professions regarding hours worked with clients in the format of caseload information regarding number of equivalent full time (FTE) positions per client age and/or diagnostic category or FTE per clinical setting [11]. Some attempts to establish benchmarks in staffing levels in specific health areas such as palliative care have been made, but few examples of published staffing ratios exist [17], with figures based on therapist-to-bed or therapist-to-patient ratios rather than evaluation of adequacy of current service provision and projections beyond this [11]. This highlights the necessity for benchmarking in terms of the allied health workforce in general, particularly with regard to service demand and prevalence of clinical population types such as neurological and rehabilitation patients, especially given the projected growth in illnesses such as dementia. Australian Labour Force Survey data [18] indicate that the number of 'other allied health workers' (dieticians, occupational therapists, podiatrists, speech professionals, audiologists, orthoptists) has increased in terms of FTE number (based on a standard working week of 35 hours) but decreased in terms of FTE rate (FTE per 100000 population), with consequent workplace shortages failing to meet the identified need and maldistribution of service provision to rural, remote and indigenous communities. From 2001 to 2006, service provision in nuclear medicine grew by $11.8 \%$, but the workforce size decreased by $4.9 \%$ [19]. This is also reflected in international data; successive reports by the General Dental Council (UK) showed that, while the dental technician workforce was declining, workloads were increasing $[20,21]$ along with dissatisfaction due to increased workload pressures [22]. In many cases, data on gender are not recorded by state and territory boards; this is being addressed for AHPRA members but has implications for a workforce that is highly feminized. Changes in the delivery settings away from institutionalbased and outpatient care to community settings ar also a driving factor in allied health affecting employment in countries such as the US and Australia [23,24].

\section{Stayers, leavers and returners-supporting a flexible and responsive workforce}

Developing a comprehensive national data set requires a broad and inclusive sampling process across the allied health population. Although professional associations outside the AHPRA ambit collect data about their members, association membership is not mandatory, and as such, this data is also incomplete. Surveys conducted to investigate demographics, employment, education and factors affecting recruitment and retention of allied health professionals have had low-response rates both here and internationally [22,25,26]; the recently published South Australian Allied Health Workforce (SAAHW) survey had an estimated combined response rate of only $18.3 \%$, with occupational response rates ranging from $57 \%$ for dietetics to $1.3 \%$ for audiology [27]. Some professions provided no responses at all. Evidence concerning recruitment, retention and turnover in the allied health literature is sparse. Amid concerns of an ageing workforce in several occupations, the 2011 census shows proportionately higher numbers of allied health professionals in the younger age groups (up to 39 years). But put in context, these figures are less reassuring-research has shown the impact of generational issues in a tight labour market and that attrition and turnover are higher among Generation Y employees $[19,28]$. A recent allied health survey indicated that, although of the $42 \%$ who intended leaving their current job within 5 years $28 \%$ gave retirement as the reason [27], a significantly larger proportion of the Generation $\mathrm{Y}$ respondents indicated that they intended leaving their job within 2 years (46\%). Surveys have shown that almost half the nuclear medicine technologist workforce is aged less than 30 years; many leave before completing 10 years in practice [19]. An earlier study into the same profession found a third of respondents to that survey had less than 3 years experience, creating a constantly young workforce with limited experience [29]. Similarly, published data on speech pathology indicated that those aged 
under 34 years were more likely to be looking for a new career and that $31 \%$ of those surveyed intended to change jobs [30]. No planning has been done at a national level with respect to this generational point at issue [31].

\section{Professional development and service delivery}

It is generally accepted that Australia will continue to experience increasing demand for health-care workers and at a rate that will challenge Australia's training and service delivery systems [32]. Student registration was launched nationally for the first time in Australia in 2011, but again, this only applies to professions registered under the NRAS agreement. Although the supply of graduates from universities is gradually increasing, government policy and benchmarks remain unchanged [33]. Profession accreditation requirements are one of the key issues affecting universities in virtually all health profession courses; a major determining factor in setting clinical placement requirements is professional accreditation [34]. This increase in university places has not necessarily been paralleled by clinical placements or an increase in supervisor numbers, although once again this is being addressed by the Health Workforce Australia clinical placement data set [35]. Access to clinical placements is seen as a constraint on growth in all jurisdictions. This can be seen in professions such as podiatry. At 3738 members, it is by far the smallest of the core allied health group, with one of the fewest numbers of students in approved programmes of study [36]. Statistics from Medicare Australia show that demand for podiatry services increased more than five times over the 2008-2009 period in some areas. Additionally, national labour force statistics show podiatry has a growth outlook of $302 \%$ over 2 years [37]. The factors driving workforce shortages compound one another-university planning decisions are influenced primarily by student and then workforce demand, which itself is influenced by perceptions of likely employment outcomes, and population and demographic change [34]. However, the current training system has insufficient capacity and structure to provide workers in a timely manner to meet demand, further driving worker shortages. US research has highlighted the need for greater information on 'career ladder programmes' to make the concept of career progression a reality for entry-level and low-wage health-care workers [23].

\section{Benefits of registration}

Beyond the need for current and consistent data to use in workforce planning, there are additional advantages to increased coverage of registration for allied health, in particular, the need to establish clear and unambiguous standards of professional competence. A registration and accreditation scheme as provided by AHPRA across all allied health professions provides the necessary safeguards for professionals and their clients to ensure quality services are provided by people with the requisite skills and knowledge to practise, as has been established in the UK with the Professional Standards Authority for Health and Social Care [38]. It provides standardization, credibility and greater professional identity [39]. This increases public confidence that variations in quality of care are minimized and safety is optimized [38]. The benefit and value to society is self-evident. Educational programmes benefit from an individual credentialing entity to prepare students for certification [39].

Research both here and overseas has demonstrated that allied health professionals are more likely to stay with an organization when they are able to attain higher levels of competency and professional development, there is good peer support in the workplace and interprofessional collaboration and workplaces encourage 'continuous learning cultures' $[28,40]$. UK professional bodies require higher education institutions to provide evidence of inter-professional education as a key process to enable collaboration [41], which is recognized as benefiting both the professional experience and patient care [42]. Although the number of allied health professionals with higher degrees is growing, research funding is still extremely small when compared to that in other areas of health care [43]. A requirement of the move towards an evidence-based culture is a critical mass of health-care professionals either in a position to conduct research or to implement scientific findings [44]. Without registration and the emphasis on evidence-based practice programmes [45], associated allied health practitioners may find themselves left behind due to lack of research skills, research not transferable to practise, and lack of managerial support for ongoing research. Smaller professions with less visibility are also at risk of reduced funding for workforce development and education [46].

\section{Costs of registration}

There are likely to be significant costs to a national registration scheme. Apart from the bureaucracy required to manage the data collection and good governance, there will be costs imposed on allied health professionals required to fill in forms, gather data and participate. Acting on the complaints and issues that arise will also engender resources and could open up a range of high costs arising from litigation. Privacy concerns and confidentiality issues are likely to make registration and accreditation yet more complex and cumbersome.

\section{International relevance}

The extent to which data are available for other countries is not surprisingly highly variable. A summary can 
be accessed from the OECD website [47]. At one extreme are countries such as Poland and Sweden who have no information to describe dentists, pharmacists, physiotherapists, psychologists, dieticians, audiologists and speech therapists and laboratory assistants. This clearly is inadequate for workforce planning. In contrast, Chile has the National Health Human Resources Information System of the public sector that includes all public hospitals, but no data are available for the private health sector. The Czech Republic benefits from annual reports produced by the Institute of Health Information and Statistics of the Czech Republic. Information arises for individual hospitals and other therapeutic institutes by profession, and the measurements of staff are made by head counts and full-time equivalents to discriminate between employees on payroll and contractual workers. Denmark reports head counts via the National Board of Health and only public sector staff are included. Full descriptions of data sources are available from the OECD for Austria, Belgium, Canada, Germany, Hungary, Iceland, Italy, Luxembourg, Mexico, Netherlands, New Zealand, Switzerland, Turkey, United Kingdom and the United States. The relevance of this work done for the Australian setting to other countries will depend on the completeness and quality of the information collected in each setting.

\section{Conclusions}

Health workforce shortages in Australia will produce unwanted public health consequences if not addressed by policy makers [31], including contraction and even disappearance of health services in areas already experiencing major problems of access, such as remote and rural regions and the more socially and economically marginalized suburbs in urban centres [48].

Development of an efficient and effective coordinated, multidisciplinary health-care system in Australia requires a combination of evidence-based strategies and reliable workforce data to ensure that the health professions can work together in the interest of improved patient outcomes. Currently, robust evidence about the allied health professions is not available to support this objective. A wider range of professions might be included under AHPRA and representative bodies strengthened to improve the level of registration and accountability of health professionals. Worth debating in Australia is the establishment of a minimum data set for allied health professionals. Lessons could be learned from other jurisdictions such as the US Center for Health Workforce Analysis and the English Centre for Workforce Intelligence.

\section{Competing interests}

The authors declare that they have no competing interests.

\section{Authors' contributions}

All authors have participated in different parts of manuscript preparation. JC, NG and DS all contributed to the conception and revision of the manuscript. DS was responsible for research and manuscript preparation. All authors have approved the final manuscript.

\section{Acknowledgements}

This manuscript was funded through a service agreement between Royal Brisbane and Women's Hospital and Queensland University of Technology using revenue funds from the hospital allied health services.

\section{Author details}

${ }^{1}$ Institute of Health Biomedical Innovation (IHBI), School of Public Health and Social Work, Queensland University of Technology, 60 Musk Ave. Kelvin Grove, Brisbane 4059, Australia. ${ }^{2}$ Royal Brisbane and Women's Hospital, Dr. James Mayne Building, Bowen Bridge Rd., Herston, QLD 4029, Australia.

Received: 16 November 2014 Accepted: 30 April 2015

Published online: 14 May 2015

\section{References}

1. Australian Health Practitioner Regulation Agency. Australian Health Practitioner Regulation Agency Annual Report 2010-11. Melbourne: AHPRA; 2011.

2. Australian Productivity Commission. Australia's health workforce report. In. Canberra; 2005. Available at https://www.hwa.gov.au/resources/publications

3. National Alliance of Self-Regulating Health Professions. Harnessing self-regulation to support safety and quality in healthcare delivery. A comprehensive model for regulating all health practitioners. Melbourne: AHPA; 2012.

4. Australian Health Ministers Advisory Council. Consultation on options on regulation of unregistered health practitioners. In. Canberra; 2011. Available at http://www.physiotherapy.asn.au/APAWCM/Advocacy_P/Submissions/ 110415\%20options\%20for\%20regulation\%20of\%20unregistered\%20 health\%20practitioners.pdf

5. Council of Australian Governments. Intergovernmental agreement for a national registration and accreditation scheme for the health professions. In. Canberra; 2008. Available at http://www.ahwo.gov.au/natreg.asp

6. Craig Hodges Consulting. Australian's views on regulatory requirements of counsellors and qualified therapists. Summary paper of research conducted by Roy Morgan on behalf of the Australian Association of Social Workers. 2011. Available at http://www.aasw.asn.au/document/item/1819.

7. Lin V, Gillick D. Does workforce regulation have the intended effect? The case of Chinese medicine practitioner registration. Aust Health Rev. 2011;35:455-61.

8. Nancarrow S, Clark J. Accountability and accreditation in the Australian allied health context. Pract Dev Health Care. 2003;2:33-47.

9. Department of Education Employment and Workplace Relations. Job outlook. Canberra: DEEWR; 2012.

10. Statistics Medicare Allied Health 2011-2012 financial year. [http://www.human services.gov.au/].

11. Speech Pathology Australia. Productivity Commission Health Workforce Study: speech pathology Australia response. In. Melbourne; 2005.

12. Australian Health Workforce Advisory Committee. The Australian Allied Health Workforce. An overview of planning issues. 2006.

13. National Center for Health Workforce Analysis. [http://bhpr.hrsa.gov/ healthworkforce/].

14. Dawson DGM. Longer term agreements for health care services: what will they achieve? York: University of York; 1998.

15. Australian Institute of Health and Welfare. Health and Community Services Labour Force 2006. Canberra: AlHW; 2009.

16. Health workforce 2025. [http://www.hwa.gov.au/].

17. Cartmill L, Comans TA, Clark MJ, Ash S, Sheppard L. Using staffing ratios for workforce planning: evidence on nine allied health professions. Hum Res: Health; 2012. p. 10(2).

18. Australian Institute of Health and Welfare. Australia's health 2010. Canberra: AlHW; 2010

19. Adams E, Cox J, Adamson B, Schofield D. Truncated careers in nuclear medicine technology: increased job control may improve retention. Aust Health Rev. 2011;35(2):124-9. 
20. General Dental Council. Annual report and accounts 2011. Norwich; 2011. Available here http://www.gdc-uk.org/Pages/default.aspx

21. General Dental Council. Annual report and accounts 2010. Norwich; 2010. Available here http://www.gdc-uk.org/Pages/default.aspx

22. Ross M, Turner S, Ibbetson R. The impact of general dental council registration and continuing professional development on UK dental care professionals: (2) dental technicians. Br Dent J. 2012;213:E13-3.

23. Bates T, Chapman S, Kaiser J, Chan M. Allied health regional workforce analysis. In: Advancing the allied health workforce in California. San Francisco: UCSF Center for the Health Professions; 2009.

24. Department of Health. Report to the National Allied Health Professional Advisory Board on the outcomes of the Modernising Allied Health Professional Careers Programme. In. Edited by Health Do. London: DH; 2011.

25. Keane S, Smith T, Lincoln M, Fisher K. Survey of the rural allied health workforce in New South Wales to inform recruitment and retention. Aust J Rural Health. 2011;19:38-44.

26. Smith T, Fisher K, Keane S, Lincoln M. Comparison of the results of two rural allied health workforce surveys in the Hunter New England region of New South Wales: 2005 versus 2008. Aust J Rural Health. 2011;19:154-9.

27. Whitford D, Smith T, Newbury J. The South Australian allied health workforce survey: helping to fill the evidence gap in primary health workforce planning. Aust J Prim Health. 2012;18:234-41.

28. Dodd J, Saggers S, Wildy H. Retention in the allied health workforce: boomers, generation X, and generation Y. J Allied Health. 2009:38:215-9.

29. Adams E, Cox J, Adamson B, Schofield D. A profile of nuclear medicine technologist practice. Nucl Med Commun. 2008;29:83-90.

30. McLaughlin E, Adamson B, Lincoln M, Pallant J, Coope C. Turnover and intent to leave among speech pathologists. Aust Health Rev. 2010;34:227-33.

31. Schofield T. Gendered organizational dynamics: the elephant in the room for Australian allied health workforce policy and planning? J Sociol. 2009:45:383-400

32. National Health Workforce Taskforce. Health workforce in Australia and factors for current shortages. Canberra; 2009. Available here http://www.ahwo.gov.au/documents/NHWT/The\%20health\%20workforce \%20in\%20Australia\%20and\%20factors\%20influencing\%20current\% 20shortages.pdf

33. Victorian Department of Health. Victorian medical radiations workforce supply and demand projections (2010-2030). In: Planning and Analysis Unit, Department of Health, Melbourne. Melbourne: Victorian Department of Health; 2010.

34. Health Workforce Australia. Mapping clinical placements: capturing opportunities for growth: demand (university) study 2011. Adelaide: HWA; 2011.

35. Clinical placement dataset. [http://www.hwa.gov.au/sites/uploads/ ClinPlacW_0.pdf].

36. Australian Health Practitioner Regulation Agency. Australian Health Practitioner Regulation Agency Annual Report 2011/2012. Melbourne: AHPRA; 2013.

37. Department of Education Employment and Workplace Relations. Australian Bureau of Statistics Labour Force Survey 2011. Canberra: DEEWR; 2011.

38. Professional Standards Authority for Health and Social Care. Who regulates health and social care professions? [http://www.professionalstandards.org.uk].

39. Dyson S, Greene S, Fraher E. A shortage of health information management professionals: how would we know? J Allied Health. 2004;33:167-73.

40. $2012 \mathrm{NHS}$ staff survey. [http://nhsstaffsurveys.com/cms/index.php?page= staff-survey-2012-detailed-spreadsheets].

41. Derbyshire JA, Machin Al. Learning to work collaboratively: nurses' views of their pre-registration interprofessional education and its impact on practice. Nurse Educ Pract. 2011;11:239-44

42. Hughes J, Hemingway S, Smith A. Interprofessional education: nursing and occupational therapy: could old rivals integrate? Nurse Educ Pract. 2005;5:110-20.

43. Centre for Policy in Nursing Research, Commonwealth Higher Education Management Service, the Higher Education Consultancy Group and the Research Forum for Allied Health Professions. Promoting research in nursing and the allied health professions: a report to Task Group 3. Bristol: HEFCE; 2001. Available at www.hefce.ac.uk/Pubs/hefce/ 2001/01_64.htm.

44. Hicks $C$, Hennessy D. Mixed messages in nursing research: their contribution to the persisting hiatus between evidence and practice. J Adv Nursing. 1997;25:595-601.
45. Systematic review of knowledge translation strategies in the allied health professions. [http://www.implementationscience.com/content/7/1/70].

46. Donini-Lenhoff FG. Coming together, moving apart: a history of the term allied health in education, accreditation and practice. J Allied Health. 2008;37:45-52.

47. OECD. OECD Health Statistics 2014 definitions, sources and methods. 2014 Available here: http://stats.oecd.org/fileview2.aspx?IDFile=1e140267-ce884018-91ee-10874f7cba71.

48. Duckett S. The Australian health care system. Melbourne: Oxford University Press; 2007.

\section{Submit your next manuscript to BioMed Central and take full advantage of:}

- Convenient online submission

- Thorough peer review

- No space constraints or color figure charges

- Immediate publication on acceptance

- Inclusion in PubMed, CAS, Scopus and Google Scholar

- Research which is freely available for redistribution 